\title{
Adenosquamous Carcinoma of the Ascending Colon: A Case Report and Review of the Literature
}

\author{
Jae Won Choi, Hee Ug Park \\ Department of Internal Medicine, Maryknoll Medical Center, Busan, Korea
}

An adenosquamous carcinoma is a malignancy that has both glandular and squamous histologic components. Both components are malignant and have potential to metastasize. An adenosquamous carcinoma of the large bowel is rare, and its clinicopathologic behavior is not fully understood. It is reported to be more aggressive and have a worse prognosis when it is compared with an adenocarcinoma alone. We present a case of an adenosquamous carcinoma in the ascending colon which was laparoscopically resected and followed by adjuvant chemotherapy.

Keywords: Adenosquamous carcinoma; Ascending colon

\section{INTRODUCTION}

Cancers of the colon and the rectum are increasing in Korea, and the vast majority are adenocarcinomas. Adenosquamous carcinomas are rare, and the incidence is approximately $0.06 \%$ of all colorectal malignancies [1]. Clinical manifestations are similar to those of patients with colorectal adenocarcinomas, and the diagnosis is based on histologic findings. Adenosquamous carcinomas contain both glandular and squamous components and have stronger potential for metastasis than adenocarcinomas alone [2, 3]. Thus, early detection of adenosquamous carcinomas is important, and the treatment of choice is surgical resection. Here, we report a case of an adenosquamous carcinoma in a 43-year-old female, which was found during screening colonoscopy and treated with surgical resection and adjuvant chemotherapy.

\section{CASE REPORT}

A 43-year-old female presented a large colon mass during colo-

Received: February 3, 2013 - Accepted: March 16, 2013

Correspondence to: Jae Won Choi, M.D.

Department of Internal Medicine, Maryknoll Medical Center, 121 Junggu-ro, Jung-gu, Busan 600-730, Korea

Tel: +82-51-461-2667, Fax: +82-51-465-7470

E-mail: heyjayone@gmail.com

(c) 2013 The Korean Society of Coloproctology

This is an open-access article distributed under the terms of the Creative Commons Attribution NonCommercial License (http://creativecommons.org/licenses/by-nc/3.0) which permits unrestricted noncommercial use, distribution, and reproduction in any medium, provided the original work is properly cited. noscopy for screening at another hospital. The mass was circumferential and ulcerofungating, and was located at the middle ascending colon (Fig. 1). The result of microscopic examination was reported as a moderately-differentiated adenocarcinoma, and she came to our hospital for surgical treatment. She only had constipation and had not shown any other specific symptoms or signs related with the cancer. There was no significant past medical history and no family history of colorectal cancer. The patient's serum carcinoembryonic antigen level was $1.22 \mathrm{ng} / \mathrm{mL}$, and her serum hemoglobin level was $10.9 \mathrm{~g} / \mathrm{dL}$. There was no significant abnormal result among initial laboratory findings. A computed tomographic scan of the abdomen identified a short, segmental, circumferential, irregular wall thickening on the ascending colon with enlargement of four pericolonic lymph nodes (Fig. 2). There was no evidence of distant metastasis on the positron emission tomographic scan.

A laparoscopic right colectomy with lymphadenectomy was done, and intraperitoneal organs, including the liver, did not show any abnormal appearance on inspection. Pathologic examination of the colon specimen revealed an ulcerofungating mass, measuring $6.0 \mathrm{~cm} \times 5.0 \mathrm{~cm} \times 1.0 \mathrm{~cm}$ (Fig. 3). It had invaded the periserosal fat layer and contained both of a moderately-differentiated adenocarcinoma and a well-differentiated squamous cell carcinoma on microscopic examination (Fig. 4). Finally, the mass was diagnosed as an adenosquamous carcinoma of stage IIIB (T3 N2a M0) according to the 7th edition of the colon and rectum cancer staging system published by the American Joint Committee on Cancer. After the operation, she received adjuvant chemotherapy six times with the FOLFOX4 (oxaliplatin, leucovorin, and fluoro- 


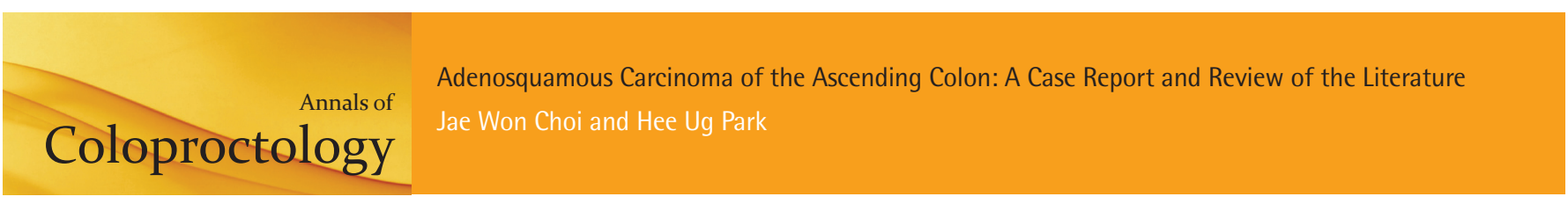

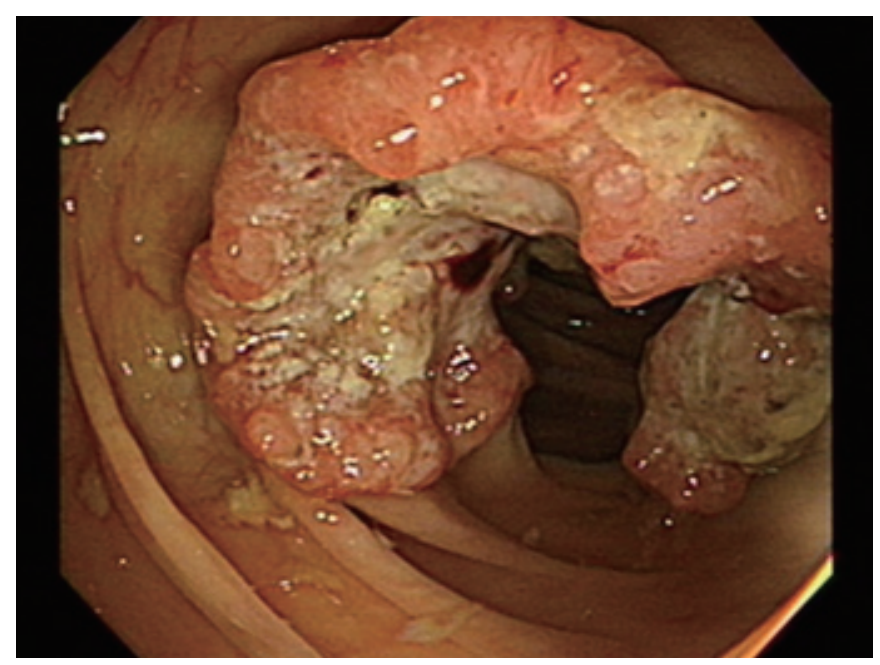

Fig. 1. Colonoscopic findings. A circumferential, ulcerofungating mass was found in the middle ascending colon during colonoscopy.

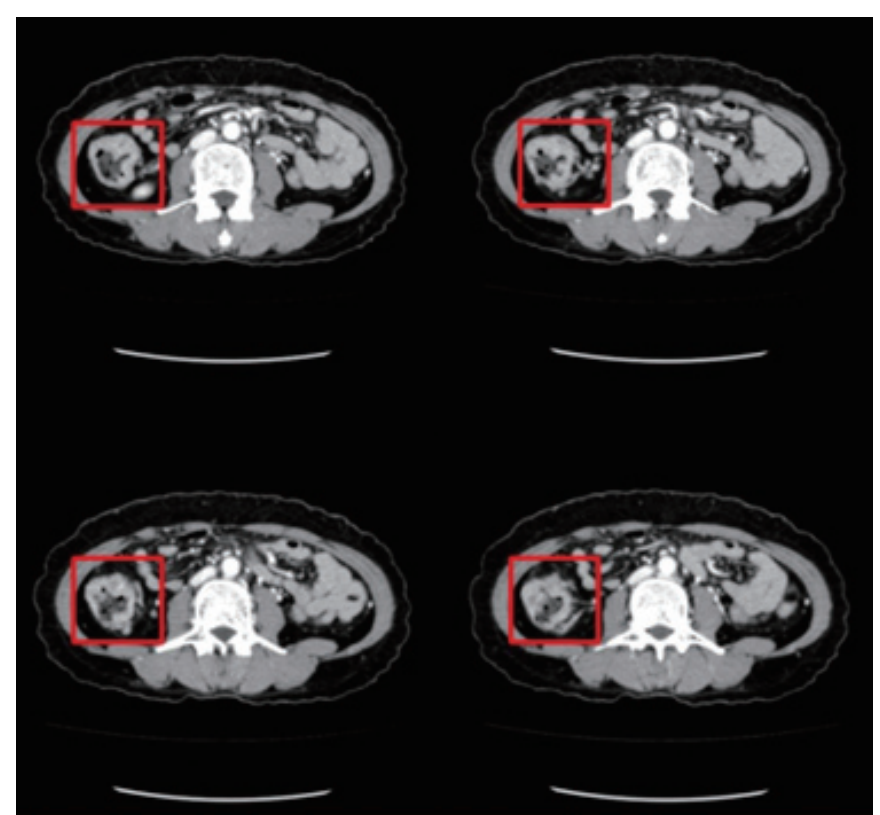

Fig. 2. Abdominal computed tomography. There was a segmental, circumferential irregular wall thickening on the ascending colon with enlargement of four pericolonic lymph nodes.

uracil) regimen. There has been no evidence of tumor recurrence during the 10 months since the completion of adjuvant chemotherapy.

\section{DISCUSSION}

An adenosquamous carcinoma in the lower gastrointestinal tract is a rare malignancy. It was first reported by Herxheimer in 1907, and subsequent reports of adenosquamous carcinomas of the co-

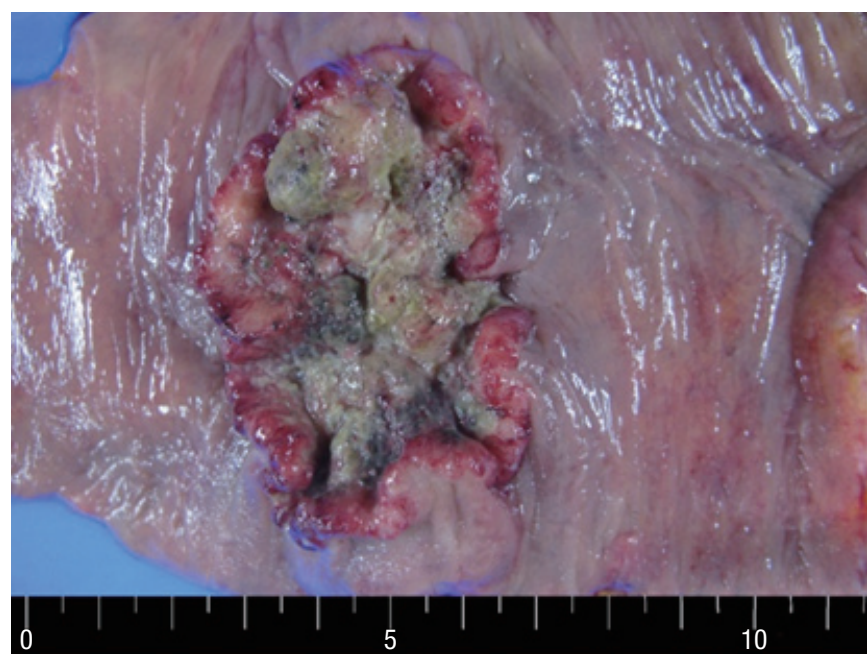

Fig. 3. Gross findings. Resected specimen revealed an ulcerofungating mass, measuring $6.0 \mathrm{~cm} \times 5.0 \mathrm{~cm} \times 1.0 \mathrm{~cm}$.

lon and the rectum are limited. In 1996, Petrelli et al. [4] described five males and two females diagnosed as having adenosquamous carcinomas. Five of them were located in the rectum, and three patients had ulcerative colitis. In 1999, Cagir et al. [1] reported 145 cases of adenosquamous carcinomas. The mean age of patients was 67 years, and the female-to-male ratio was 1.34. In the report, 53 percent of the carcinomas were located in the sigmoid colon, rectum, and anus, 28 percent in the right colon (cecum and ascending colon), and the rest in the middle segment (transverse colon and descending colon). Frizelle et al. [5] reported different results about the location. In the report on 44 patients with adenosquamous and squamous carcinomas in the colon proximal to $8 \mathrm{~cm}$ from the dentate line, right-sided lesions were most common (43 percent). Metastatic disease was evident at presentation in 49 percent of the patients, and the most common sites in order of decreasing frequency were the liver, peritoneal, and lung [5].

The histiogenesis of an adenosquamous carcinoma is not fully understood, but there are several theories $[6,7]$. These include the following: 1) the presence of embryologic nests of ectodermal cells; 2) squamous metaplasia of the intestinal mucosa; 3 ) the presence of pluripotent stem cells of endodermal origin capable of multidirectional differentiation. Although both adenomatous and squamous components have a potential for metastasis, the squamous components have a potential to metastasize more frequently and more aggressively [2, 3].

It has also been proposed that an abnormal mucosal stimulus from conditions such as ulcerative colitis [8], schistosomiasis [9], radiation [10], or human papilloma virus may allow squamous metaplasia and subsequent development of the tumor. Patients with adenosquamous carcinomas may present with paraneoplastic syndromes such as hypercalcemia [11].

There is an association with previous or synchronous colorectal adenocarcinomas. In some case reports, adenocarcinomas of the 

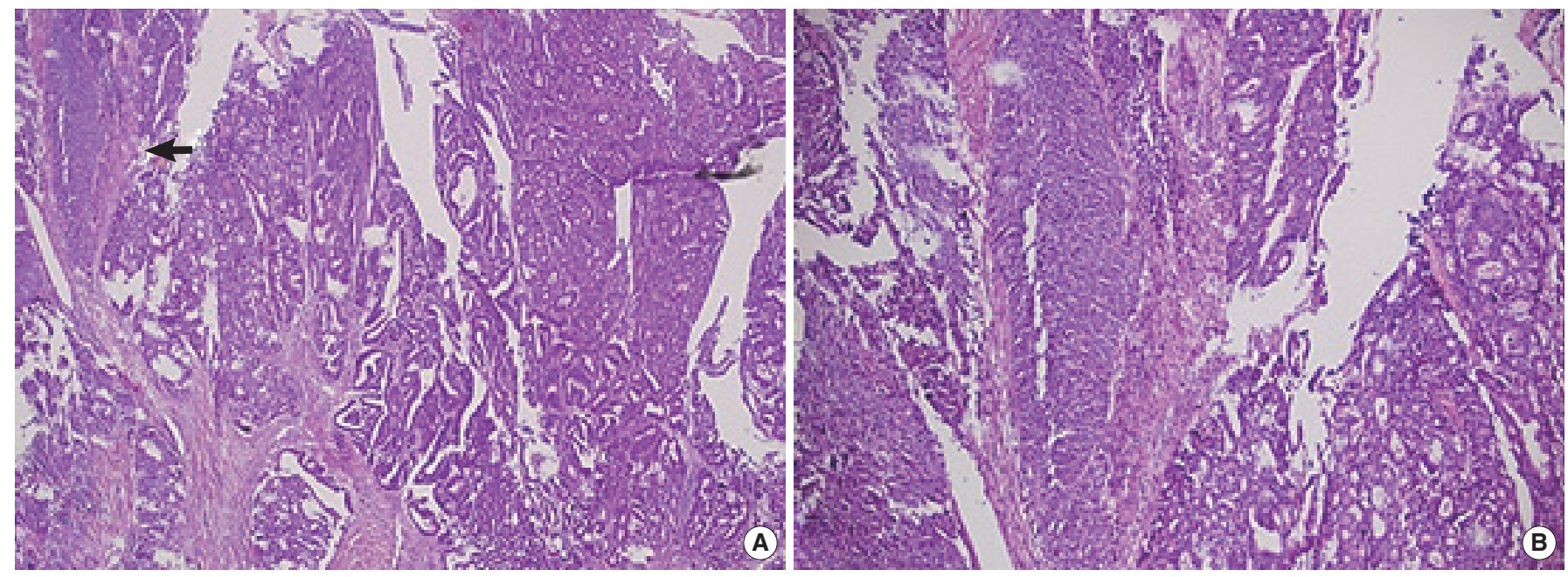

Fig. 4. Microscopic findings. (A) The mass was composed of a moderately-differentiated adenocarcinoma and a well-differentiated squamous cell carcinoma (arrow) $(\mathrm{H} \& \mathrm{E}, \times 40)$. (B) The squamous part of the carcinoma was confirmed $(\mathrm{H} \& \mathrm{E}, \times 200)$.

colon had occurred between three months and 15 years before the detection of the primary squamous-cell carcinomas of the large bowel [12, 13]. Petrelli et al. [4] described synchronous adenocarcinomas of the colon in association with squamous and adenosquamous carcinomas, respectively, which suggests that clinicians should be aware that adenosquamous carcinomas often do not present as solitary neoplasms and should investigate the whole colon thoughtfully.

The prognosis for an adenosquamous carcinoma is known to be worse than that for an adenocarcinoma. In a review of 145 cases, Cagir et al. [1] reported that the mean patient survival was 12 months and that the overall survival was $30.7 \%$. In the report, patients with distal segment lesions had a statistically significant longer survival compared with those with proximal and middle lesions. This may be due to the earlier diagnosis of adenosquamous carcinomas in the distal segment. Frizelle et al. [5] found that the prognosis is different according to the stage of the carcinoma. For stage I to II node-negative disease (Dukes A and B), the prognosis was similar to that for colorectal adenocarcinomas. However, when nodal disease occurred, the prognosis was worse than that for adenocarcinomas of similar stage. For node-positive and node-negative disease, the 5 -year survival rates were 23 and 85 percent, respectively. Features predicting a poor prognosis included right-sided lesions, ulcerated or annular carcinomas, node-positive disease, grade 3 or 4 cancer and stage IV disease.

The treatment of choice for adenosquamous carcinomas is surgical excision. It is not sufficient to remove only the entire tumor; rather, the regional mesenteric draining lymphatics must also be removed. Adjuvant chemotherapy with semustine, 5-fluorouracil, carmustine, or methotrexate have been used; however, the exact impact of these drugs on outcome is not known yet [4]. Also, there was a case report on a combination of radiotherapy and chemotherapy directed at the squamous component [14]. As the prognosis of node-positive patients with adenosquamous carcinomas is poor and there have been favorable results from chemotherapy and radiation therapy for colorectal cancers [15], it seems appropriate to consider the place of adjuvant therapy in the management.

In conclusion, adenosquamous carcinomas of the colon are rare and have worse prognosis than adenocarcinomas. Early detection and radical surgical excision is important, and adjuvant therapy can be considered, although its efficacy has not been proven yet.

\section{CONFLICTS OF INTEREST}

No potential conflict of interest relevant to this article was reported.

\section{ACKNOWLEDGMENTS}

The authors thank Dr. Hye Sook Kim for preparing the pathologic specimens.

\section{REFERENCES}

1. Cagir B, Nagy MW, Topham A, Rakinic J, Fry RD. Adenosquamous carcinoma of the colon, rectum, and anus: epidemiology, distribution, and survival characteristics. Dis Colon Rectum 1999; 42:258-63.

2. Kontozoglou TE, Moyana TN. Adenosquamous carcinoma of the colon--an immunocytochemical and ultrastructural study. Report of two cases and review of the literature. Dis Colon Rectum 1989; 32:716-21.

3. Cerezo L, Alvarez M, Edwards O, Price G. Adenosquamous carcinoma of the colon. Dis Colon Rectum 1985;28:597-603. 
4. Petrelli NJ, Valle AA, Weber TK, Rodriguez-Bigas M. Adenosquamous carcinoma of the colon and rectum. Dis Colon Rectum 1996;39:1265-8.

5. Frizelle FA, Hobday KS, Batts KP, Nelson H. Adenosquamous and squamous carcinoma of the colon and upper rectum: a clinical and histopathologic study. Dis Colon Rectum 2001;44:341-6.

6. Comer TP, Beahrs OH, Dockerty MB. Primary squamous cell carcinoma and adenocanthoma of the colon. Cancer 1971;28: 1111-7.

7. Steele VE, Nettesheim P. Unstable cellular differentiation in adenosquamous cell carcinoma. J Natl Cancer Inst 1981;67:149-54.

8. Michelassi F, Montag AG, Block GE. Adenosquamous-cell carcinoma in ulcerative colitis: report of a case. Dis Colon Rectum 1988;31:323-6.

9. Wiener MF, Polayes SH, Yidi R. Squamous carcinoma with schistosomiasis of the colon. Am J Gastroenterol 1962;37:48-54.

10. Pittella JE, Torres AV. Primary squamous-cell carcinoma of the cecum and ascending colon: report of a case and review of the literature. Dis Colon Rectum 1982;25:483-7.

11. Chevinsky AH, Berelowitz M, Hoover HC Jr. Adenosquamous carcinoma of the colon presenting with hypercalcemia. Cancer 1987;60:1111-6.

12. Lyttle JA. Primary squamous carcinoma of the proximal large bowel: report of a case and review of the literature. Dis Colon Rectum 1983;26:279-82.

13. Vezeridis MP, Herrera LO, Lopez GE, Ledesma EJ, Mittleman A. Squamous-cell carcinoma of the colon and rectum. Dis Colon Rectum 1983;26:188-91.

14. Schneider TA 2nd, Birkett DH, Vernava AM 3rd. Primary adenosquamous and squamous cell carcinoma of the colon and rectum. Int J Colorectal Dis 1992;7:144-7.

15. Gastrointestinal Tumor Study Group. Prolongation of the diseasefree interval in surgically treated rectal carcinoma. N Engl J Med 1985;312:1465-72. 